\title{
Lancefield group C streptococcal endocarditis
}

\author{
P. F I N N G A N,M .X.M . F I T Z G E R A L D ${ }^{1}$, \\ G. C U M M N G, a n d A. M. GE D D E S
}

Department of Medicine, University of Birmingham, Queen Elizabeth Hospital, Birmingham, and Department of Communicable and Tropical Diseases, East Birmingham Hospital, Birmingham

\begin{abstract}
Finnegan, P., Fitzgerald, M. X. M., Cumming, G., and Geddes, A. M. (1974). Thorax, 29, 245-247. Lancefield group C streptococcal endocarditis. Three cases of endocarditis due to Lancefield group $C$ streptococcus are reported. These organisms are of low pathogenicity and they are infrequently responsible for infection in man. The cases reported emphasize, however, that they may cause serious and fatal illness.
\end{abstract}

There are four sub-groups of Lancefield group C streptococcus: Strep. dysgalactiae, Strep. equi, Strep. equisimilis, and Strep. zooepidemicus. They are mainly pathogens of animals causing mastitis in cattle and strangles in horses. The organisms are often present in the human female genital tract and have been isolated from the skin, pharynx, and urine (Duma, Weinberg, Medrek, and Kunz, 1969). They are of low pathogenicity and usually non-invasive but they may cause minor indolent skin lesions and pharyngitis. Wound sepsis and puerperal infections have also been observed, but septicaemia is extremely rare. There are only four previously reported cases of endocarditis due to group C streptoccus (Rosenthal and Stone, 1940; Sanders, 1963; Feingold, Stagg, and Kunz, 1966; Bullock, Cruz, Rabin, and Sonnenwirth, 1960).

\section{CASE REPORTS}

CASE I R.N., a 43-year-old man, was known to have had a cardiac murmur all his life but was asymptomatic. Three weeks before admission he had a brief episode of gastroenteritis which subsided spontaneously. Two weeks later he complained of nausea, vomiting, and rigors. These symptoms had persisted for two days when he suddenly developed slurred speech and the left arm and leg became paralysed.

On admission he was pyrexial $\left(40^{\circ} \mathrm{C}\right)$, and extensive ecchymoses were present on the trunk and limbs. There was no finger clubbing nor splinter haemorrhages and the spleen was not palpable. He had a motor dysphasia, a left homonymous hemianopia, and a left hemiplegia. The pulse was regular and a grade $4 / 6$ pansystolic murmur accompanied by a thrill was present in the mitral area.

'Present address: Boston University School of Medicine
Laboratory tests showed the following: Haemoglobin $13 \mathrm{~g} / 100 \mathrm{ml}$; ESR $16 \mathrm{~mm} / \mathrm{hr}$ (Westergren). Microscopic haematuria was noted on four occasions. Seven blood cultures yielded a growth of streptococci which were subsequently shown to belong to Lancefield group $\mathrm{C}$. They were grouped using the acid extraction method and Burroughs Wellcome \& Co. antisera. Negative results were obtained using the antisera for the other Lancefield groups. The organisms were sensitive to penicillin, but tube dilution sensitivity tests were not done. A presumptive diagnosis of bacterial endocarditis with cerebral embolism was made and he was treated with benzyl penicillin in a dose of 20 million units daily given intravenously. A slight pyrexia persisted for five weeks and treatment was continued for eight weeks. During the course of the illness the haemoglobin fell to $8 \mathrm{~g} / 100 \mathrm{ml}$ and the ESR rose to $64 \mathrm{~mm} / \mathrm{hr}$. Cardiac catheterization (Table) showed no evidence of an intracardiac shunt and it was concluded that he had a mild degree of mitral incompetence. When last seen in September 1972 he was continuing to show functional improvement from the left hemiplegia and there was no evidence of deterioration in cardiac function.

T A B L E

CARDIAC CATHETERIZATION DATA

\begin{tabular}{|c|c|c|c|c|c|c|}
\hline \multirow[t]{2}{*}{ Case } & \multicolumn{2}{|c|}{$\underset{\left(1 / \mathrm{min} / \mathrm{m}^{2}\right)}{\text { Cardiac Index }}$} & \multicolumn{2}{|c|}{$\begin{array}{c}\text { Mean Pul- } \\
\text { monary Arterial } \\
\text { Pressure } \\
\text { (mmHg) }\end{array}$} & \multicolumn{2}{|c|}{$\begin{array}{c}\text { Mean Pul- } \\
\text { monary Wedge } \\
\text { Pressure } \\
\text { (mmHg) }\end{array}$} \\
\hline & Rest & Exercise & Rest & Exercise & Rest & Exercise \\
\hline II & $\begin{array}{l}3 \cdot 0 \\
8 \cdot 0\end{array}$ & $\begin{array}{r}5 \cdot 0 \\
13 \cdot 0\end{array}$ & $\begin{array}{l}14 \\
21\end{array}$ & $\begin{array}{l}26 \\
40\end{array}$ & $\begin{array}{l}7 \\
6\end{array}$ & 14 \\
\hline II & $\begin{array}{r}\text { Oxyg } \\
\text { SV } \\
62 \\
\text { Pulm } \\
24:\end{array}$ & $\begin{array}{c}\text { saturatio } \\
\text { IVC } \\
58 \\
\text { ary to sys }\end{array}$ & $\begin{array}{l}(\%) \\
\text { RA } \\
72 \\
\text { mic flo }\end{array}$ & $\begin{array}{r}\text { RV } \\
79 \\
\text { atio }\end{array}$ & $\begin{array}{l}\text { PA } \\
79\end{array}$ & \\
\hline
\end{tabular}


CASE II N.T., a 40-year-old male cattle-truck driver with no history of heart disease, was kicked by a cow in September 1969 and developed a septic skin lesion. Three months later he had a dental abscess treated by extraction with no antibiotic cover. The patient was a stoical individual and although ankle swelling was noticed by his employers in April 1970 he did not seek medical attention until February 1971.

Physical examination revealed that he was very ill. He had a collapsing pulse, the arterial pressure was $130 / 60 \mathrm{mmHg}$, and the apex beat was in the sixth left intercostal space, $2 \mathrm{~cm}$ outside the mid-clavicular line. There were continuous systolic and diastolic murmurs accompanied by a thrill maximal at the lower left sternal edge. The jugular venous pressure was raised, there was marked ascites, and considerable pitting oedema of the feet, legs, and abdominal wall. The liver and spleen were enlarged but there were no splinter haemorrhages nor finger clubbing. A single haemorrhage was present in the right optic fundus.

Laboratory tests showed: Haemoglobin $8.0 \mathrm{~g} / 100 \mathrm{ml}$, leucocyte count $6,000 / \mathrm{mm}^{3}$, platelet count 190,000 , serum urea $175 \mathrm{mg} / 100 \mathrm{ml}$, creatinine $5.9 \mathrm{mg} / 100 \mathrm{ml}$; serum complement $8 C^{\prime}$ units (normal values $=35 \pm 4 \cdot 7$ units). There were haematuria and proteinuria (2-3 $\mathrm{g} / \mathrm{l})$; the proteinuria was non-selective on electrophoresis and the urine deposit contained red blood cells and hyaline and granular casts. Radiographically the transverse diameter of the heart was increased and there was a left pleural effusion. The electrocardiogram was normal except for slight ST segment depression in the left ventricular leads. Streptococci were isolated from three blood cultures and were identified as Lancefield group C organisms. The acid extraction method and Burroughs Wellcome \& Co. antisera were used and negative results were obtained using antisera for the other Lancefield groups. The organisms were sensitive to penicillin but tube dilution sensitivity tests were not performed.

Treatment was begun with benzyl penicillin (20 million units intravenously daily), digoxin, frusemide, and spironolactone. Initial progress was satisfactory but after one week he developed extensive pulmonary oedema which failed to improve with large doses of parenteral frusemide and ethacrynic acid. His renal function also deteriorated and the serum urea rose to $240 \mathrm{mg} / 100 \mathrm{ml}$. Peritoneal dialysis was performed for a total of 36 hours and this reduced the serum urea to $87 \mathrm{mg} / 100 \mathrm{ml}$ and removed 12 litres of fluid. Thereafter the renal function continued to improve and the signs of cardiac failure disappeared.

Cardiac catheterization data are shown in the Table. During root aortography dye passed into the right ventricle and through the tricuspid valve into the right atrium. The presence of a sinus of Valsalva fistula was confirmed by passage of the catheter from the aorta to the right ventricle.

At operation in September 1971, Mr. L. D. Abrams found a bicuspid aortic valve and aneurysmal dilatation of the anterior sinus of Valsalva. A fistulous tract led from the aneurysm to the right ventricle, the opening being hidden within the chordae of the tricuspid valve. The fistula was excised and the open- $\overline{\bar{O}}$ ing was closed.

Postoperative recovery was rapid and uneventful $\vec{\nabla}$ and 12 months later he had good cardiac and renal function and the only abnormality on clinical exam- $\infty$ ination was a short aortic diastolic murmur.

CASE III A.B., a 65-year-old woman, was admitted to $\vec{\omega}$ East Birmingham Hospital with a short history of $\stackrel{\curvearrowright}{\rightarrow}$ profuse diarrhoea and fever. On admission she was very ill with marked dehydration and peripheral i circulatory failure. There was an apical pansystolic murmur. Chest radiography showed cardiac enlarge- iN ment and pulmonary oedema.

A presumptive diagnosis was made of septicaemia and acute endocarditis, possibly caused by a salmonella species in view of the profuse diarrhoea. Treatment was started with $100 \mathrm{mg}$ of trimethoprim and $500 \mathrm{mg}$ of sulphadiazine given separately intravenously every six hours. Thirty-six hours after admission, intravenous therapy was replaced by oral co-trimoxazole.

Streptococci of Lancefield group $C$ were isolated $\underset{A}{D}$ from blood cultures. The organisms were identified by the acid extraction method and Burroughs Wellcome \& Co. antisera; negative results were obtained with antisera for the other Lancefield groups. The $\overline{\bar{D}}$ organisms were sensitive to penicillin, co-trimoxazole, 응

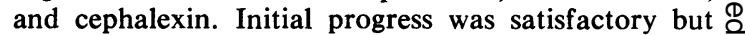
nine days after admission the patient developed a skin $\vec{F}$ rash and treatment was therefore changed to oral $\frac{0}{3}$ cephalexin in a dose of $500 \mathrm{mg}$ every six hours. She continued to improve but suddenly developed acute left ventricular failure which failed to respond to treatment.

Necropsy showed cardiac enlargement (455 g) and 응 left ventricular hypertrophy. The mitral valve had $\stackrel{x}{0}$ vegetations on its surface and one of the chordae tendineae was ruptured. The brain contained an abscess in the right parietal lobe and there was a $\delta$ septic infarct in the spleen. Cultures taken at necropsy from the spleen, brain, mitral vegetations, and blood 음 were all sterile.

\section{DISCUSSION}

Streptococci of Lancefield group $\mathrm{C}$ cause human \% disease infrequently. Rantz and Keefer (1941) $\widetilde{O}$ found that of 1,159 strains of $\beta$ haemolytic $\tilde{\omega}$ streptococci isolated in human infections only 14 ? $(1.2 \%)$ belonged to group C. In a study of 1400 patients with streptococcal bacteraemia, Duma $\stackrel{\overparen{D}}{\overparen{D}}$ et al. (1969) found only one patient in whom a $\stackrel{?}{+}$ group C streptococcus was isolated from the blood. 뭉 Cherubin and Neu (1971), in a survey of 656 cases of infective endocarditis, found that none was caused by Lancefield group $C$ streptococcus.

There are only four previously reported cases of endocarditis due to Lancefield group C strepto- 
coccus. The first case, reported by Rosenthal and Stone (1940), was a young woman with no previous history of heart disease who developed a septicaemia following a septic abortion. In the case reported by Sanders (1963) there was a history of a septic abortion 10 months previously. In two other cases (Feingold et al., 1966; Bullock et al., 1970) there was no obvious source of infection. It is noteworthy that these four infections occurred in women with no preceding history of heart disease.

In cases I and III reported by us there was a preceding gastrointestinal illness, but no link between this and the subsequent endocarditis was established. In our case II there were two possible sources of infection: the patient was in close daily contact with animals which may have been harbouring the organism and a septic skin lesion developed after he was kicked by a cow. He also had a dental extraction without antibiotic cover. These events antedated his hospital admission by more than 12 months but the development of ankle swelling four months after the dental treatment probably indicates the existence of cardiac or renal disease at that time. It is likely that the renal lesion was an immune complex glomerulonephritis secondary to the endocarditis. Cases I and III had no animal contacts.

The organisms were all sensitive to penicillin and the infection was eradicated in cases $I$ and II. Vegetations were present on the mitral valve at necropsy in the third case but they were sterile on culture and rupture of the chordae tendineae was probably responsible for death.

Our three patients were severely ill and there was an acute onset in cases I and III. In case II there is circumstantial evidence that the illness was a protracted one; the endocarditis was probably subacute and started on the bicuspid aortic valve. The sinus of Valsalva fistula eventually eroded into the right ventricle and the serious haemodynamic effects of this occurrence were responsible for the rapid clinical deterioration.
It is evident that Lancefield group C streptococcus can produce both acute and subacute endocarditis and, although considered to be of low pathogenicity, it may cause serious and fatal disease.

The authors wish to acknowledge with gratitude the help of Dr. P. P. Brown and Dr. F. A. J. Bridgwater. Dr. J. A. Wakes-Miller kindly referred case II. We are indebted to Mr. L. D. Abrams for the operation details of case II. We also thank Miss J. Rawlinson for typing the manuscript.

\section{REFERENCES}

Bullock, J. D., Cruz, M. G., Rabin, E. R., and Sonnenwirth, A. C. (1970). A fatal case of group C streptococcal endocarditis. Missouri Medicine, 67, 595.

Cherubin, C. E. and Neu, H. C. (1971). Infective endocarditis at the Presbyterian Hospital in New York City from 1938 to 1967. American Journal of Medicine, 51, 83.

Duma, R. J., Weinberg, A. N., Medrek, T. F., and Kunz, L. J. (1969). Streptococcal infections. A bacteriologic and clinical study of streptococcal bacteremia. Medicine (Baltimore), 48, 87.

Feingold, D. S., Stagg, N. L., and Kunz, L. J. (1966). Extra-respiratory streptococcal infections. Importance of the various serologic groups. New England Journal of Medicine, 275, 356.

Rantz, L. A. and Keefer, C. S. (1941). The distribution of hemolytic streptococci groups $\mathrm{A}, \mathrm{B}$, and $C$ in human infections. Journal of Infectious Diseases, 68, 128.

Rosenthal, A. H. and Stone, F. M. (1940). Puerperal infection with vegetative endocarditis: report of sulfanilamide therapy in two fatal cases due to Streptococcus haemolyticus groups B and C. Journal of the American Medical Association, 114, 840.

Sanders, V. (1963). Bacterial endocarditis due to a group C hemolytic streptococcus. Annals of Internal Medicine, 58, 858.

Requests for reprints to: Dr. G. Cumming, Midhurst Medical Research Institute, Midhurst, Sussex. 